\title{
Women Family Physicians' Personal Experiences in the Republic of Moldova
}

\author{
Lorraine S. Wallace, $P h D$, and Iurie Brinister, $M D, M B A$
}

Background: As part of the former Soviet Union, the Moldovan health system was highly centralized and geared toward inpatient care. The objective of this study was to explore the personal experiences of female family physicians in Chişinău, Moldova.

Methods: A purposeful sample of female family physicians was recruited to participate in this study. A professional translator conducted in-depth interviews using an 8-item semistructured questionnaire to capture personal practice experiences, scope of practice, and beliefs. Verbatim responses were summarized using a continuous iterative process.

Results: Twenty female family physicians (mean age, $42.4 \pm 7.2$ years; mean clinical experience, $12.2 \pm 7.9$ years) were included in the sample. Analysis of the data illuminated 4 key themes: (1) family medicine, as a specialty, offered much diversity and personal satisfaction; (2) appointment time restraints and paperwork demands posed significant challenges to providing care to patients; (3) problems faced by patients were complex and went far beyond the leading causes of morbidity and mortality; and (4) patients generally have a limited amount of health-related knowledge, but increased access to health information was bridging this gap.

Conclusion: Although family medicine is a rewarding career, system-related factors posed significant challenges, not only in providing quality care but in day-to-day satisfaction. ( $\mathrm{J}$ Am Board Fam Med 2010;23:783-789.)

Keywords: Moldova, Women Physicians

The Republic of Moldova, landlocked between Romania and the Ukraine, is one of the poorest countries of the ex-Soviet Union, with a per capita gross domestic product of US\$2400 purchasing power parity. ${ }^{1}$ The country, with a total population of approximately 4.3 million, also includes the autonomous region of Transnistria. After the dissolution of the Soviet Union in 1991, the Republic of Moldova proclaimed its dependence in 1992.

This article was externally peer reviewed.

Submitted 13 April 2010; revised 26 May 2010; accepted 10 June 2010.

From the Department of Family Medicine, University of Tennessee Graduate School of Medicine, Knoxville (LSW); and the School of Public Health, Moldova State University of Medicine and Pharmacy, Chişinău (IB).

Funding: This work was supported, in part, by a 20092010 Fulbright Scholarship (LSW).

Conflict of interest: none declared.

Corresponding author: Lorraine S. Wallace, $\mathrm{PhD}$, Department of Family Medicine, University of Tennessee Graduate School of Medicine, 1924 Alcoa Highway, U-67, Knoxville, TN 37920 (E-mail: lwallace@mc.utmck.edu).
As part of the former Soviet Union from 1940 to 1991, the Moldovan health system was highly centralized and geared toward inpatient and multispecialty care, with little focus on preventive care. As a result, policy makers in the Republic of Moldova faced significant obstacles as they struggled to reform their health care system in the midst of considerable instability after the collapse of the Soviet Union. Although significant strides have been made during the past 2 decades, per-head expenditure on health in Moldova, at US\$90 in 2007, is far below both neighboring countries of Romania and the Ukraine as well as other former ex-Soviet Union republics, including Estonia, Belarus, Georgia, and Turkmenistan. ${ }^{2}$ Furthermore, although compulsory health insurance was mandated in 2004, approximately half of Moldovan adults lack health insurance coverage. ${ }^{3}$

The specialty of family medicine did not exist in the Republic of Moldova before the fall of the Soviet Union. Following the lead of more developed nations, the establishment of family medicine as a discipline in Moldova was viewed as a major 
necessary step aimed at modernizing the health care system to meet the needs of its citizens. Therefore, 2 initiatives were used to develop family medicine as a specialty. ${ }^{4}$ The first step involved retraining a subset of practicing specialists to become family physicians. In addition, a family medicine residency program was established in 1997 at the sole medical school in Moldova, thereby allowing newly graduated physicians the opportunity to pursue a 3 -year training program to become family physicians. As a result of these initiatives, by 2008 there were nearly 2000 family physicians practicing throughout the Republic of Moldova. ${ }^{5}$

Although the scope of family medicine has changed in the Republic of Moldova during the past decade, to our knowledge no studies have examined the role of family medicine from a practicing physician's perspective. Therefore, to address this gap in the literature, the purpose of this study was to explore the personal experiences of female family physicians practicing full-time in the greater Chişinău, Moldova, area. Almost three quarters of family physicians in the Republic of Moldova are women. Chişinău, the country's capital, is also the largest city in and economic hub of the Republic of Moldova.

\section{Methods}

\section{Sampling Strategy}

With the assistance of the professional translator, one of the authors (IB) contacted clinic directors at 3 separate family medicine practices via telephone and/or E-mail and provided each of them with an overview of the study. These family medicine practices, located in different districts throughout Chişinău, were identified by this author (IB) because they served diverse patient populations and were accessible to the research team. One of the clinics was affiliated with the Moldova State University of Medicine and Pharmacy whereas the other 2 family medicine clinics were housed within larger polyclinics (multispecialty clinics).

All clinic directors were willing to participate in the study and arranged for individual family physicians to be interviewed in a private room (eg, conference room or empty patient examination room) at their respective clinics. Two interview days were scheduled at each respective clinic, and 2 to 5 family physicians interviewed during each session. All family physicians who had scheduled patient ap- pointments (approximately $50 \%$ of the total family physicians at each location) in their respective clinics on set interview half-days participated in the study. All of the family physicians practicing at each of these 3 clinical locations were women.

\section{Development of the Semistructured Questionnaire}

Based on a thorough review of literature, one author (LSW) developed an 8-item, semistructured questionnaire to capture personal practice experiences, scope of practice, and beliefs of female family physicians. Specifically, open-ended questions included (1) Why did you choose to be a family doctor? (2) Can you please tell me what you do on a "typical" day? (3) How many patients do you see on a "typical" day? (4) In your opinion, what are the top 3 health problems facing Moldovans today? (5) Are your patients well informed (have a good understanding) about health issues? (6) Where do most of your patients "get" their health information? (7) What do you like the most about being a family doctor? and (8) What do you like the least about being a family doctor?

\section{Data Collection}

The primary author (LSW; a native English speaker) and a professional translator (a native Romanian and Russian speaker and fluent in English) conducted in-depth interviews during a 3 month period (November 2009 through January 2010). Between 2 and 5 family physicians were interviewed individually during 1 of 6 scheduled interview days. Based on each family physician's personal preference, in-depth interviews were conducted in either Romanian or Russian.

With the aid of the professional translator, the first author (LSW) described the study purpose to each family physician. The Institutional Review Board at Moldova State University of Medicine and Pharmacy approved the study protocol and all family physicians gave informed consent before being interviewed. Neither the first author (LSW) nor the professional translator had a previous relationship with any of the family physicians.

The professional translator administered the open-ended questions to each interviewee. Immediately after they responded to each question, the professional translator provided an English translation to the primary author (LSW). Next, each response was recorded verbatim and the translator clarified responses with the family physician if nec- 
essary. In addition, when deemed appropriate, the family physicians were asked to elaborate on and/or clarify their initial responses to gather more detailed and representative accounts of their personal experiences. We also collected the following demographic information from each family physician: age, original medical residency training specialty, and year of completion of medical residency.

Each semistructured interview took between 20 and 30 minutes to complete in its entirety. The first author (LSW) and professional translator held a short debriefing session at the conclusion of each interview to clarify issues that had been discussed. Furthermore, the primary author (LSW) summarized findings immediately after each of the 6 data collection sessions.

\section{Data Analyses}

Responses were entered verbatim, as presented by the professional translator, from each semistructured interview into a Microsoft Access (Microsoft Corp., Redmond, WA) database and these were summarized using a continuous iterative process. We used the Statistical Package for the Social Sciences for Windows version 17.0 (SPSS, Inc., Chicago, Illinois) for all descriptive analyses (frequencies, means, SD).

This study used grounded theory qualitative methods in which a set of guidelines are used to collect and analyze data. Grounded theory methodology not only guides the manner in which data are collected and analyzed in the field, ${ }^{6,7}$ but also entails having a comprehensive understanding of individual experiences before unique cases are aggregated. Theories based on "thick-rich descriptions" are constructed about the observed phenomena "grounded" in the context of the real-world experiences of the participants. ${ }^{7,8}$

Using a thematic content analysis, the interview data were coded, or broken down, into manageable categories. The categories/themes were reviewed by both authors and a consensus was reached to confirm that summaries to each question were representative of the family physicians interviewed collectively.

\section{Results}

Data saturation, when we were gathering no new information, was reached after the completion of 17 semistructured interviews. However, because one more day of semistructured interviews already had been scheduled before it was recognized that data saturation had been reached, 3 additional interviews were conducted. Therefore, a total of 20 female family physicians, with an average age of 42 years, practicing full-time in the greater Chişinău area made up our final sample (see Table 1).

Eleven of the participants did not originally complete residency training to become a family physician. Most were initially trained as pediatricians $(n=10)$, whereas one was a therapeutic physician. Those retrained as family physicians reported either receiving $4(n=4)$ or $6(n=7)$ months of family medicine specialty training. Family physicians at all 3 clinical locations reported seeing an average of $22.9 \pm 4.7$ (range, 15-35) patients during the course of an 8- to 9-hour work day (8:00 AM to 5:00 or 6:00 PM). Typically, these family physicians spent half of the day caring for scheduled patients in the clinic and the other half of the day making home visits (on average, 5-6 per day) and completing paperwork.

Analysis of the data illuminated 4 key themes: (1) family medicine, as a specialty, offered much diversity and personal satisfaction; (2) appointment time restraints and paperwork demands posed significant challenges to providing care to patients; (3) problems faced by patients are complex and go far beyond the leading causes of morbidity and mortality; and (4) patients generally have a limited amount of

Table 1. Sociodemographic Characteristics of Female Family Physicians

\begin{tabular}{lccc}
\hline & & \multicolumn{2}{c}{ Originally Trained as a Family } \\
Physician
\end{tabular}

Values provided as mean $\pm \mathrm{SD}$. 
health-related knowledge, but increased access to health information was bridging this gap.

\section{Family Medicine as a Specialty Offered Much Diversity and Personal Satisfaction}

Although approximately half of the women in our sample were required to retrain as a family physician, the majority felt that their careers were both professionally and personally rewarding. One of the main reasons family medicine was exciting was because, "You never know what the next case is. [Family medicine] forces you to use all the knowledge you learned at university." Physicians entering family medicine directly from medical school did so for reasons such as, "I just liked the job. I didn't choose family medicine for financial reasons for sure," and "[with] hospitalized patients, you make no progress there. If I worked in the hospital, I would have to work in a specific section and only treat one disease. In family medicine I can work with all patients."

One of the bright spots of being a family physician was the ability to provide medical care to entire families. As one physician expressed, "I like the work because you get to know entire families. My patients are like my extended family. When I get results, it makes me very happy." Similarly, family physicians also enjoyed caring for patients of all ages. One physician noted, "I like caring for all 'children,' regardless of their age [insinuating that all patients are children]"; another physician said, "I like that I get the patient from the belly." Family physicians received a great deal of personal satisfaction when their patients' health improved, and this was voiced by several physicians: "I'm happy when I get results and see patients feeling better."

Alternatively, one of the professional frustrations faced by these family physicians was their lower status perceived by patients as compared with specialists. As voiced by one family physician, "People don't consider a family physician important in their lives. They don't appreciate their family physician, but they do specialists." From a personal perspective, family physicians felt that the demands placed on them limited the amount of personal time available to them. For instance, several physicians expressed that, "There's no time for my family and children."

\section{Appointment Time Restraints and Paperwork Demands Posed Significant Challenges to Providing Care to Patients}

Family physicians typically spent one half of the day seeing patients in their respective clinics. With most patient visits scheduled for approximately 15 minutes each, physicians overwhelmingly thought they had an insufficient amount of time to spend with each patient. For example, one physician explained, "The fixed times for appointments are frustrating. All patient visits are set, regardless of what each individual patient needs." Another physician noted, "We have too many patients and not enough time. There is only one medical assistant per family physician. That's just not enough." Collectively, in the eyes of these physicians, time constraints posed significant challenges to providing comprehensive patient care.

On average, physicians spent approximately half of the day making visits to patients' homes. In most cases, physicians had to either walk or take public transportation to patients' homes. Most physicians viewed home visits as an important part of their responsibilities in assuring quality patient care. These family physicians especially enjoyed caring for newborns and their mothers in their homes. However, as noted by several physicians, there were also some drawbacks to making home visits. For instance, one physician noted, "I'm frustrated by 'false' home visits," and another physician said, "It takes time to travel and the street dogs are a hazard." Furthermore, as noted by one physician, positive steps have been made in an attempt to improve efficiency and ease of travel: "I walk to patients' homes, but some polyclinics do have cars now to see patients, which is helpful."

As voiced by most physicians, the amount of paperwork that had to be completed-much of it mandated by the Ministry of Health-was excessive and interfered with time available to care for patients. One physician stated, "There's too much paperwork and much of it is unnecessary." On the other hand, another physician noted that paperwork-related tasks were becoming less time consuming as a result of the adoption of an electronic medical record (EMR), "There's lots of paperwork, but it is easier now with the electronic medical record." 


\section{Problems Faced by Patients Are Complex and Go Far Beyond the Leading Causes of Morbidity and Mortality}

All family physicians identified leading causes of morbidity and mortality-hypertension, diabetes, hepatitis, and tuberculosis-as significant health problems among their patient populations. However, a common thread that emerged throughout the interviews was that patients' problems went far beyond their physical health. For example, one physician noted, "I hear stories of sadness and their personal circumstances that make life hard. For example, most patients have very little money." Another family physician expressed that, "People are nervous and unhappy with their lives. They bring all their problems [beyond health-related] to their family physician." Those interviewed felt that many patients exhibited symptoms of depression that needed to be addressed.

\section{Patients Generally Have a Limited Amount of Health-Related Knowledge, but Improved Access to Health Information Was Bridging This Gap}

Overall, family physicians felt that many patients had limited health-related knowledge. Several explanations were voiced by different physicians as to the underlying reasons that contributed to patients' limited fund of health-related knowledge. For example, one physician stated, "What they know depends on their general education level," while another explained, "Most patients are not informed because they don't have time to worry about their health. They also don't get taught [about their health] and don't come to the doctor very much." Another physician expressed that some patients are apathetic because "some of my patients don't want to be informed or listen to me."

Adequately treating patients who have chronic diseases was a challenge faced by many physicians. Treating patients with hypertension was a significant frustration for several physicians because their patients do not feel sick. As described by one physician, "Most patients with hypertension do not understand it. It is hard to convince them to come back to the clinic." On the other hand, physicians expressed that younger patients were becoming more cognizant of their personal health-related choices. For example, one physician noted, "About half of my patients pay attention to health behaviors such as tobacco [use], diet, and alcohol [use]."
Physicians voiced that greater access to health information via the mass media has helped to increase patients' health-related knowledge to some degree during recent years. Specifically, a physician stated, "Patients are becoming more informed because of television and the Internet, although much of what patients find on the Internet is different from what I say." Physicians were also encouraged with the impact group visits had on increasing patients' health-related knowledge. For instance, one physician said, "My patients are getting better though. Many are better informed by attending group visits [for pregnancy, diabetes, hypertension, breast cancer] led by physicians and nurses at our clinic."

\section{Discussion}

The results of this qualitative examination into the scope of practice and personal experiences of female family physicians practicing full-time in the capital city of Chişinău revealed that family medicine as a specialty offered much diversity and personal satisfaction. Although practicing as a family physician was personally rewarding, system-related factors such as appointment time restraints and paperwork demands posed significant challenges to providing quality care to patients. As described by these family physicians, we also found that not only were many of the problems faced by patients complex in nature but they often were compounded by patients' limited fund of health-related knowledge.

Most women in our sample expressed a high degree of career satisfaction. However, mirroring a recent study of Lithuanian physicians, ${ }^{9}$ modest monetary compensation, low perceived social status, and high workload all contributed to dissatisfaction. Similar to salaries overall in Moldova, physician wages, averaging approximately $€ 180$ (US\$230) per month in 2007, are low. ${ }^{5}$ Whereas increasing physician salaries will take time, decreasing workload could be one potential avenue of raising the level of satisfaction on a daily basis. As an example, an EMR system was available at one of the 3 clinical locations visited. Importantly, physicians at this clinic reported that the EMR was a time saver. Recent studies in the United States point to the benefits of increased physician productivity after the implementation of an EMR. ${ }^{10}$ Although initially both costly and time-consuming, widespread EMR implementation throughout the Republic of Moldova could potentially aide in 
both streamlining and improving quality of patient care.

Virtually all of the female physicians expressed concern regarding workload and not having sufficient time to adequately counsel patients during scheduled appointment times. As was the case in this study, inadequate time allotted for patient visits is a universal concern; physicians currently practicing in the United Kingdom, Germany, and the United States all reported time pressures in ambulatory settings. ${ }^{11,12}$

Similar to a nationally representative US study, ${ }^{12}$ most of the physicians in our study voiced that a large proportion of their patients had complex psychosocial problems. These findings are not surprising given that the Republic of Moldova is still largely in transition and hardships such as poverty and unemployment are widespread. Lack of monetary resources and employment opportunities not only impact an individual's or family's ability to take care of their basic needs (eg, purchasing food and medicine), but often may contribute to depression as well. For example, among a sample of Lithuanians, the long-term ( $\geq 12$ months) unemployed had less sense of coherence and poorer psychosocial health (eg, depression, suicide intentions, more intensive alcohol consumption, poor selfreported health) compared with the short-term unemployed. $^{13}$

Moldovan family physicians should be cognizant of both the short- and long-term effects of poverty and unemployment on their patients' overall wellbeing. Family physicians' ability to adequately address and treat patients' psychosocial problemspredominantly depression-most often requires follow-up appointments and counseling beyond the allotted appointment time for acute problems. As was the case among Estonian family physicians, ${ }^{14}$ their Moldovan counterparts may also need additional depression-related training.

In general, family physicians reported that many of their patients had limited health-related knowledge. Mirroring these observations, data from the 2005 Moldova Health and Demographic Survey revealed that, although virtually all adults reported having heard of both tuberculosis and HIV/AIDS, knowledge regarding transmission and signs/symptoms of these diseases was much lower. ${ }^{3}$ Increasing patients' health-related knowledge is a significant challenge. However, physicians felt that the Inter- net played a significant role in providing patients with greater access to health-related information.

Several limitations should be considered when interpreting our results. First, our findings, like those of other qualitative studies, are inherently not oriented to large-scale generalizability. However, consistent with the literature, we reached data saturation at just fewer than 20 interviews. ${ }^{15}$ Second, our sample included female family physicians practicing exclusively in Chişinău. Thus, personal experiences of those interviewed in our study may not be applicable to male family physicians and/or those practicing in other areas throughout the Republic of Moldova, in particular rural locations where resources are often very limited. However, as a hypothesis-generating strategy, we gained useful information to guide us in the design of a more generalizable investigation in the future.

\section{Conclusion}

Family physicians in our study generally found their careers to be rewarding. However, systemrelated factors such as set appointment time limitations and paperwork demands posed significant challenges not only to providing quality care but to day-to-day satisfaction. Because patients who had complex psychosocial problems were routinely encountered in their clinical practices, family physicians may need more training to enable them to best care for these patients. Widespread efforts both inside and outside of the clinical setting should be used in an effort to increase healthrelated knowledge and promote healthy lifestyles.

We thank Tatiana Dumbrava for her help with recruiting physicians and translating the interviews. We are very grateful to the family physicians who gave their time to be interviewed.

\section{References}

1. Central Intelligence Agency. The world factbook. Guide to country comparisons. Available at: https:// www.cia.gov/library/publications/the-world-factbook/ geos/md.html. Accessed 23 September 2010.

2. Rechel B, McKee M. Health reform in central and eastern Europe and the former Soviet Union. Lancet 2009;374:1186-95.

3. National Scientific and Applied Center for Preventive Medicine, Ministry of Health and Social Protection. Moldova health and demographic survey, 2005. Available at: http://www.measuredhs.com/pubs/pdf/ FR178/FR178.pdf. Accessed 11 February 2010.

4. Bivol G, Curocichin G, Sutnick AI, et al. Develop- 
ment of family medicine education in Moldova with Carelift International. Educ Health (Abingdon) 2002;15:202-14.

5. Cruc O, Banciu O, Brinişter I, Vremiş M, Craievschi-Toartă V, Sinchetru A. Study on social protection and social inclusion in Moldova. Available at: http:// ec.europa.eu/social/main.jsp?langId = ro\&catId $=89 \&$ newsId=662\&furtherNews=yes. Accessed 23 March 2010.

6. Glaser BG, Strauss AL. The discovery of grounded theory: strategies for qualitative research. Chicago: Aldine; 1967.

7. Charmaz K. Grounded theory: objectivist and constructivist methods. In: Denzin NK, Lincoln YS, eds. Handbook of qualitative research, $2^{\text {nd }}$ ed. London: Sage Publications, Inc.; 2000:509-35.

8. Patton, M. Qualitative evaluation and research methods, $2^{\text {nd }}$ ed. Newbury Park: Sage Publications; 1990.

9. Buciuniene I, Blazeviciene A, Bliudziute E. Health care reform and job satisfaction of primary health care physicians in Lithuania. BMC Fam Pract 2005; 6:10.

10. Brotzman GL, Guse CE, Fay DL, Schellhase KG,
Marbella AM. Implementing an electronic medical record at a residency site: physicians' perceived effects on quality of care, documentation, and productivity. WMJ 2009;108:99-103.

11. Konrad TR, Link CL, Shackelton RJ, et al. It's about time: physicians' perceptions of time constraints in primary care medical practice in three national healthcare systems. Med Care 2010;48:95-100.

12. McMurray JE, Linzer M, Konrad TR, Douglas J, Shugerman R, Nelson K. The work lives of women physicians results from the physician work life study. The SGIM Career Satisfaction Study Group. J Gen Intern Med 2000;15:372-80.

13. Stankūnas M, Kalediene R, Starkuviene S. Sense of coherence and its associations with psychosocial health: results of survey of the unemployed in Kaunas. Medicina (Kaunas) 2009;45:807-13.

14. Oöpik P, Aluoja A, Kalda R, Maaroos HI. Family doctors' problems and motivating factors in management of depression. BMC Fam Pract 2006;7:64.

15. Guest G, Bunce A, Johnson L. How many interviews are enough? An experiment with data saturation and variability. Field Methods 2006;18:59-82. 